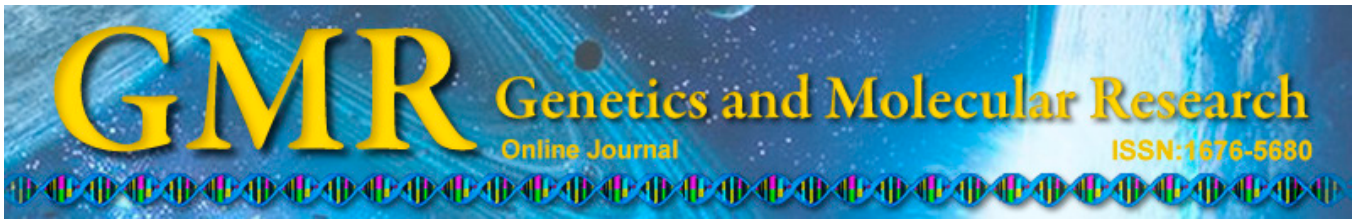

\title{
Relationship between vitamin $D$ receptor (VDR) polymorphisms and the efficacy of recombinant human growth hormone (rhGH) treatment in children with idiopathic short stature
}

\author{
W. Wang ${ }^{1 *}$, X.P. Luo ${ }^{2 *}$, L.X. Cai ${ }^{1 *}$, Z.R. Cui ${ }^{1}$, X.Y. Luo ${ }^{1}$ and R.K. Luo ${ }^{3}$ \\ ${ }^{1}$ Pediatric Endocrinology Clinic, \\ Third Affiliated Hospital of Zhengzhou University, Zhengzhou, Henan, China \\ ${ }^{2}$ Department of Pediatrics, Tongji Hospital, Tongji Medical College, \\ Huazhong University of Science and Technology, Wuhan, Hubei, China \\ ${ }^{3}$ Zhengzhou Foreign Language School, Zhengzhou, Henan, China \\ *These authors contributed equally to this study. \\ Corresponding author: W. Wang \\ E-mail: weiwang169@126.com
}

Genet. Mol. Res. 14 (3): 10507-10514 (2015)

Received February 3, 2015

Accepted May 18, 2015

Published September 8, 2015

DOI http://dx.doi.org/10.4238/2015.September.8.12

\begin{abstract}
Polymorphisms in the vitamin D receptor (VDR) gene are associated with idiopathic short stature (ISS) in several countries. This study aimed to identify a possible correlation between polymorphisms in the VDR promoter in Chinese children with ISS and the efficacy of the recombinant human growth hormone (rhGH) treatment. Pre-pubertal children with ISS and healthy age- and gendermatched children ( $\mathrm{N}=95$ each) were enrolled in this study. Two single nucleotide polymorphisms (SNPs) in the VDR promoter (rs11568820 at the Cdx-2-binding site upstream of exon 1e and rs4516035 at -1012 upstream of exon 1a) were typed. The growth velocity, standard
\end{abstract}


deviation score (SDS) of height for chronological age, height SDS for bone age, predicted adult height, and serum insulin-like growth factor 1 (IGF-1) and IGF-binding protein 3 (IGFBP-3) levels of the ISS patients were determined before and 6 months after rhGH treatment. No significant differences were observed in the genotype frequencies between the ISS cases and controls. After rhGH treatment, the growth velocity of the $\mathrm{A} / \mathrm{G}$ genotype at the Cdx-2-binding site SNP locus was significantly higher than that of the G/G genotype; the IGF-1 and IGFBP-3 levels were also higher in the treated group than the untreated group. However, these changes were independent of the VDR-promoter genotype. Polymorphisms in the VDR promoter may not result in the pathogenesis of ISS in Chinese children. The A/G genotype showed a significantly higher growth velocity than the G/G genotype, and may represent a short-term marker of growth potential.

Key words: Idiopathic short stature; VDR; Insulin-like growth factor 1; rhGH; Insulin-like growth factor-binding protein 3

\section{INTRODUCTION}

Idiopathic short stature (ISS) is a condition wherein the height of an individual is more than 2 standard deviations (SD) below the corresponding mean height of individuals belonging to a given age, gender, and population group. ISS constitutes the overwhelming majority of subjects evaluated for short stature in pediatric endocrine clinics. The pathogenesis of ISS is multifactorial, and is influenced by systemic and local hormones, nutritional factors, lifestyle, and genetic factors that remain to be comprehensively characterized. The reported heritability of height is $75 \%$ (Choi et al., 2013).

Vitamin D receptor (VDR) polymorphisms are associated with adult height. Polymorphisms in the VDR promoter were correlated in Korean children with ISS by Minamitani et al. (1998) and Choi et al. (2013). Functional analyses have demonstrated that a polymorphism in the VDR-binding element (VDRE) of the GH1 promoter contributes to isolated growth hormone deficiency. The VDRE in the human GH1 promoter acts as a negative regulator of GH1 transcription (Giordano et al., 2008). The regulation of transcriptional activity by promoter regions of the VDR appears to have a substantial influence on height.

Functional studies have assigned different physiological processes and diseases to each polymorphism in the VDR gene (Jehan et al., 2010). These studies have identified the BsmI, ApaI, TaqI, and FokI loci as the four enzyme loci that contribute to the development of multiple sclerosis, asthma, and cancer (Poon et al., 2013; Atoum and Tchoporyan, 2014; Kalman and Toldy, 2014). Dempfle et al. (2006) reported that a functional SNP in the VDR gene may contribute to $34 \%$ of the ISS cases in a population. The more transcriptionally active allele of the functional FokI SNP (rs 10735810) is overrepresented in children affected with ISS, and may contribute to short stature (Dempfle et al., 2006). The exon 2 polymorphism affecting the VDR mRNA and protein is one of the most important determinants of adult height, especially in female Japanese subjects (Minamitani et al., 1998). The steroid receptor coactivator 3 (SRC-3) maintains the circulation of insulin growth factor 1 (IGF-1), by enhancing the expression of IGF-binding protein 3 (IGFBP-3) through VDR regulation (Liao et al., 2008). d'Alésio 
et al. (2005) reported that the effect of the VDR promoter genotype on growth might specifically involve the growth plate cartilage function. VDR promoter genotype may contribute to growth via variations in the transactivation capacity of the VDR promoter, in addition to other VDR promoter polymorphisms that influence the stability of the VDR mRNA or the length of the VDR protein (d'Alesio et al., 2005).

Recombinant human growth hormone (rhGH) is the only treatment for ISS, and is known to evoke a variable response in the patients. The main aim of this study was to determine the possible correlation between two polymorphisms in the VDR promoter, rs 11568820 at the Cdx-2-binding site upstream of exon 1e and rs4516035 at -1012 upstream of exon 1a, and the occurrence of ISS in Chinese children; in addition, we attempted to determine if genotyping could guide individual therapy.

\section{MATERIAL AND METHODS}

\section{Subjects}

Ninety-five pre-pubertal children with ISS $(8.2 \pm 1.4$ years old, 61 males and 34 females) and 95 healthy age- and gender-matched children of normal height were selected, from among the patients of the pediatric endocrinology clinic of the Third Affiliated Hospital of Zhengzhou University between July 2012 and July 2014, for this study. Written informed consent was obtained from all participants, and the study was approved by the Institutional Review Board of the Third Affiliated Hospital of Zhengzhou University.

The patients were selected based on the following inclusion criteria: short stature, a condition wherein the height of an individual was more than 2 SD below the corresponding mean height of individuals belonging to a given age, gender, and population group; normal weight and height at birth; peak growth hormone (GH) levels $>10 \mathrm{ng} / \mathrm{mL}$ in at least two GH stimulation tests; normal thyroid, heart, and kidney function; normal blood and urine; and a history of treatment (for at least 6 months) with rhGH $(\sim 0.35-0.42 \mathrm{mg} / \mathrm{kg})$ (Wit et al., 2008; Ismail et al., 2011; Sandoval et al., 2014). The exclusion criteria included the presence of chronic organic diseases, GH deficiencies, chromosomal abnormalities, skeletal dysplasia, genetic metabolic diseases, thyroid dysfunction, and psychosocial deprivation, as well as use of medication that interferes with GH secretion or function and small size for gestational age at birth.

\section{Methods}

Height, weight, secondary sexual characteristics, pelvic ultrasound of the uterus and ovaries (girls), or testicular volume (for boys; measured using a testicle mold) were recorded at 3-month intervals (judged by two trained doctors). A single X-ray of the left wrist was obtained to determine the bone age. The predicted adult height (PAH) and genetic target height (THt) [the height of father $(\mathrm{cm})+$ height of the mother $(\mathrm{cm}) \pm 13) /(2 \pm 5)$ ] values were calculated, and IGF-1 and IGFBP-3 levels in serum were measured before and 6 months after rhGH treatment (measured by the chemiluminescent method, IMMULITE 2000). Bone age was judged by at least two trained observers, using the Greulich and Pyle method, and PAH was determined using the Bayley-Pinneau method (Sotos and Tokar, 2014). The growth velocity, standard deviation score (SDS) of height for chronological age (HtSDSca), and height 
SDS for bone age (HtSDSba), was calculated using the normal height of children in nine cities, measured during 2005, as a reference ( 6 cases discontinued treatment of rhGH during the study period).

\section{Genotyping}

Two milliliter of fasting venous blood was collected from each individual in EDTA anticoagulant tubes. Genomic DNA was extracted using a QuickGene DNA Whole Blood Kit S (Kurabo, Osaka, Japan), and cryopreserved at $-20^{\circ} \mathrm{C}$ until genetic analysis.

PCR amplification was performed in a total volume of $50 \mu \mathrm{L}$, composed of $3 \mu \mathrm{L}$ genomic DNA, $1 \mu \mathrm{L}$ of each of the oligonucleotide primers, $25 \mu \mathrm{L} 2 \mathrm{X}$ PCR buffer for KOD DNA polymerase, $5 \mu \mathrm{L}$ dNTPs $(2 \mathrm{mM}), 2 \mu \mathrm{L} \mathrm{MgSO}_{4}(25 \mathrm{mM}), 1 \mu \mathrm{L}$ KOD DNA polymerase $(1 \mathrm{U} / \mu \mathrm{L})$, and $12 \mu \mathrm{L}$ distilled water. The PCR conditions were set as follows: an initial denaturation step at $94^{\circ} \mathrm{C}$ for $2 \mathrm{~min}$, followed by 35 cycles of denaturation at $98^{\circ} \mathrm{C}$ for $10 \mathrm{~s}$, annealing at $55^{\circ} \mathrm{C}$ for $30 \mathrm{~s}$, and extension at $68^{\circ} \mathrm{C}$ for $1 \mathrm{~min}$. The PCR products were purified and subsequently sequenced using a 3730XL DNA Analyzer (Applied Biosystems, Waltham, MA, USA). Genotype analyses were conducted using the Genemapper software (v.4.0; Applied Biosystems). Table 1 summarizes the primer sets and product sizes. Figure 1 shows the sequencing map.

\begin{tabular}{llc}
\multicolumn{2}{c}{ Table 1. Polymerase chain reaction primer sequences and amplification products. } \\
\hline Gene & Primer sequences & Product size $(\mathrm{bp})$ \\
\hline$V D R(r s 11568820)$ & F: GGATCCCAAAAGGAAAGGAA & 578 \\
$V D R(r s 4516035)$ & R: TGAGAGACATGAGCGTGGAG & 571 \\
& F: TGAGTCTCAGCTTCCCTGGT & \\
\hline
\end{tabular}

VDR, vitamin D receptor.

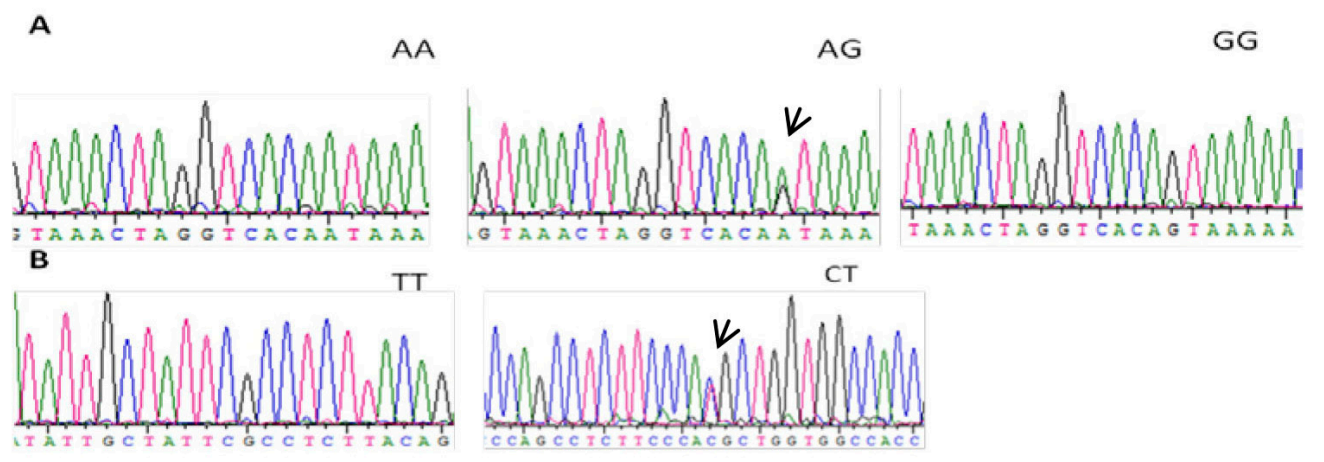

Figure 1. A. rs11568820 SNP at the Cdx-2-binding site upstream of exon 1e. B. rs4516035 SNP -1012 bp upstream of exon 1a. The heterozygote peak is indicated by the arrow.

\section{Statistical analysis}

The obtained data were statistically analyzed using the SPSS v.17.0 software platform (IBM, Armonk, NY, USA). All data are reported as means \pm SD. The means of continuous 
variables were compared using the Student $t$-test. The allelic and genotypic frequencies of each SNP were compared using the chi-square test. Differences were considered to be statistically significant at $\mathrm{P}<0.05$.

\section{RESULTS}

\section{Distribution of the VDR polymorphisms}

The genotypes at the Cdx-2-binding site SNP locus were distributed as follows: $18.9 \%$ $\mathrm{G} / \mathrm{G}, 56.8 \% \mathrm{G} / \mathrm{A}$, and $24.2 \% \mathrm{~A} / \mathrm{A}$ in the ISS patients, and $23.2 \% \mathrm{G} / \mathrm{G}, 58.9 \% \mathrm{G} / \mathrm{A}$, and $17.9 \%$ $\mathrm{A} / \mathrm{A}$ in the control subjects. The genotype composition ratios $\left(\chi^{2}=1.336, \mathrm{P}=0.513\right)$ and allelic frequencies $\left(\chi^{2}=1.053, \mathrm{P}=0.305\right)$ did not differ significantly between the two groups. The frequencies of the $\mathrm{T} / \mathrm{T}$ and $\mathrm{C} / \mathrm{T}$ genotypes at the $-1012 \mathrm{SNP}$ locus in ISS patients and control subjects were 91.6 and $96.8 \%(\mathrm{~T} / \mathrm{T})$ and 8.4 and $3.2 \%(\mathrm{C} / \mathrm{T})$, respectively. The genotype composition ratio $\left(\chi^{2}=2.412, \mathrm{P}=0.120\right)$ and allelic frequencies $\left(\chi^{2}=2.340, \mathrm{P}=0.126\right)$ also did not differ significantly between the two groups (Table 2 ).

Table 2. Sequential determination of vitamin D receptor polymorphisms.

\begin{tabular}{|c|c|c|c|c|c|c|}
\hline & \multicolumn{3}{|c|}{ rs 11568820} & \multicolumn{3}{|c|}{ rs 4516035} \\
\hline & GG & GA & AA & $\mathrm{TT}$ & $\mathrm{CT}$ & $\mathrm{CC}$ \\
\hline Case $(\%)$ & 18 (18.9) & $54(56.8)$ & $23(24.2)$ & 87 (91.6) & $8(8.4)$ & $0(0)$ \\
\hline Control (\%) & $22(23.2)$ & $56(58.9)$ & 17 (17.9) & $92(96.8)$ & $3(3.2)$ & $0(0)$ \\
\hline
\end{tabular}

\section{Relationship between the VDR promoter SNP and clinical parameters of children with ISS}

No significant differences were observed in the HtSDSca, growth velocity, PAH, or THt in ISS children prior to rhGH treatment, based on the genotype ( $\mathrm{P}>0.05$; Table 3$)$.

Table 3. Growth parameters of children with idiopathic short stature before treatment with recombinant human growth hormone.

\begin{tabular}{|c|c|c|c|c|c|c|c|}
\hline & \multicolumn{4}{|c|}{ rs 11568820} & \multicolumn{3}{|c|}{ rs4516035 } \\
\hline & GG & $\mathrm{AG}$ & AA & $\mathrm{P}$ & TT & $\mathrm{CT}$ & $\mathrm{P}$ \\
\hline $\mathrm{N}$ & 17 & 51 & 21 & & 82 & 7 & \\
\hline Age (in years) at the initiation of treatment & $8.2 \pm 1.0$ & $8.3 \pm 1.5$ & $7.9 \pm 1.4$ & 0.618 & $8.2 \pm 1.4$ & $8.1 \pm 0.9$ & 0.817 \\
\hline $\mathrm{GV0}(\mathrm{cm} /$ year $)$ & $3.8 \pm 0.9$ & $3.8 \pm 0.8$ & $4.0 \pm 0.9$ & 0.651 & $3.9 \pm 0.9$ & $3.9 \pm 0.7$ & 0.954 \\
\hline HtSDSca & $-2.4 \pm 0.6$ & $-2.5 \pm 0.8$ & $-2.4 \pm 0.7$ & 0.646 & $-2.5 \pm 0.8$ & $-2.4 \pm 0.7$ & 0.851 \\
\hline PAH0-THt & $2.1 \pm 0.6$ & $2.5 \pm 0.9$ & $2.4 \pm 0.7$ & 0.383 & $2.4 \pm 0.9$ & $2.4 \pm 0.7$ & 0.903 \\
\hline
\end{tabular}

HtSDSca, height standard deviation score (SDS) for chronological age; HtSDSba, height SDS for bone age; GV0, pre-treatment growth velocity; PAH0, predicted adult height before treatment; THt, genetic target height.

\section{Correlation between the VDR promoter SNP and response to rhGH}

The individuals with the $\mathrm{A} / \mathrm{G}$ genotype in the ISS group showed a significantly higher growth velocity compared to those with the $\mathrm{G} / \mathrm{G}$ genotype $(\mathrm{P}=0.022)$; on the other hand, no 
significant differences were observed between the $\mathrm{T} / \mathrm{T}$ and $\mathrm{C} / \mathrm{T}$ genotypes $(\mathrm{P}=0.662)$.

The children in the control group demonstrated no significant differences in the growth velocity according to genotype $(\mathrm{P}>0.05)$.

The differences in $\triangle \mathrm{HtSDSca}$ and $\Delta \mathrm{HtSDSba}$ were not correlated to the VDR promoter polymorphism $(\mathrm{P}>0.05)$. The serum IGF-1 and IGFBP-3 levels in children with ISS improved after treatment; however, this difference was not associated with a specific VDR promoter genotype $(\mathrm{P}>0.05$; Table 4$)$.

Table 4. Changes in growth parameters of children with idiopathic short stature 6 months after recombinant human growth hormone (rhGH) treatment.

\begin{tabular}{|c|c|c|c|c|c|c|c|}
\hline \multirow[t]{2}{*}{ Genotype } & \multicolumn{4}{|c|}{ rs11568820 } & \multicolumn{3}{|c|}{ rs 4516035} \\
\hline & GG & $\mathrm{AG}$ & AA & $\mathrm{P}$ & TT & $\mathrm{CT}$ & $\mathrm{P}$ \\
\hline$\Delta \mathrm{GV6}$ & $4.6 \pm 1.0^{\mathrm{a}}$ & $5.5 \pm 1.4^{b}$ & $5.1 \pm 1.2$ & 0.064 & $5.2 \pm 1.3$ & $5.4 \pm 1.3$ & 0.662 \\
\hline$\Delta \mathrm{HtSDSca}$ & $0.32 \pm 0.1$ & $0.33 \pm 0.1$ & $0.35 \pm 0.1$ & 0.649 & $0.33 \pm 0.1$ & $0.34 \pm 0.1$ & 0.843 \\
\hline$\Delta \mathrm{HtSDSba}$ & $0.15 \pm 0.1$ & $0.16 \pm 0.1$ & $0.14 \pm 0.1$ & 0.708 & $0.15 \pm 0.1$ & $0.14 \pm 0.1$ & 0.716 \\
\hline$\Delta \mathrm{IGF}-1(\mu \mathrm{g} / \mathrm{L})$ & $136.7 \pm 34.5$ & $144.7 \pm 50.9$ & $144.5 \pm 43.6$ & 0.819 & $142.7 \pm 46.6$ & $148.1 \pm 44.4$ & 0.769 \\
\hline$\Delta \mathrm{IGFBP}-3(\mu \mathrm{g} / \mathrm{L})$ & $4.0 \pm 0.7$ & $4.3 \pm 1.0$ & $3.9 \pm 0.8$ & 0.176 & $4.2 \pm 0.9$ & $4.2 \pm 0.7$ & 0.950 \\
\hline
\end{tabular}

Values with a superscript small letter "a" were compared with those with superscript small letter " $b$ " $(\mathrm{P}=0.022)$; $\Delta \mathrm{GV} 6, \Delta \mathrm{HtSDSca}, \Delta \mathrm{HtSDSba}, \Delta \mathrm{IGF}-1$, and $\triangle \mathrm{IGFBP}-3$ represent the differences in growth velocity, standard deviation score (SDS) of height for chronological age, height SDS for bone age, insulin-like growth factor 1, and IGF-binding protein 3, respectively.

\section{DISCUSSION}

Global genome scans conducted to genetically determine the height loci have identified a peak of linkage with adult height at the chromosome marker D12S398 locus on chromosome 12 (d'Alesio et al., 2005). Interestingly, the VDR gene is located at the chromosome locus 12q13.1, which is close to the peak of linkage (d'Alesio et al., 2005; Ambler et al., 2013). Therefore, the VDR gene, identified by genome scan studies, could be a genetic determinant of adult height.

VDR is an important regulator of biological processes, including tissue and cell growth and differentiation, bone metabolism, and modulation of immune responses (Gao et al., 2010; Kaarthikeyan et al., 2013). VDR affects the cell proliferation or differentiation in the growth plates of long bones by altering one or more factors via mutations in the Phex gene (Jehan et al., 2008). Previous reports have suggested that $1,25-(\mathrm{OH})_{2} \mathrm{D}$ increases the circulating IGF-1 levels in vivo and in bone cell cultures; in addition, it increases the expression of IGF-type 1 receptors in growth plate chondrocytes, and several IGF-binding proteins in osteoblasts and bone marrow stromal cell cultures (d'Alesio et al., 2005).

In this study, no differences were observed in the genotype composition ratio and allele frequency between the subject groups, although the growth velocity of subjects with the $\mathrm{A} / \mathrm{G}$ genotype at the Cdx-2-binding site was significantly higher than that of subjects with the G/G genotype. Increased serum IGF-1 and IGFBP-3 levels were observed in the treated subjects compared to the levels observed at pre-treatment, although this increase was independent of the VDR promoter (rs11568820) genotype.

The frequency of the A/A genotype at the Cdx-2-binding site locus (rs11568820) upstream of exon 1e may be responsible for ISS in Korean children (Choi et al., 2013), in con- 
trast to our findings. Cdx-2 is differentially expressed in normal stomach and intestinal tissue, and is known to decrease progressively in patients with gastric intestinal metaplasia, dysplasia, and cancer. Moreover, Cdx-2 expression is associated with bone mineral density and susceptibility to fractures in the elderly (Orlow et al., 2012). Cdx-2 polymorphism is located in the DNA-binding portion of the gene, and therefore likely influences other transcriptional processes; polymorphisms in the VDR gene promoter region are important for the regulation of calcium absorption (Rowland et al., 2012). Casado-Díaz et al. (2013) reported that female carriers of the A allele have a lower risk of osteoporosis compared to the carriers of the $\mathrm{G}$ allele. The A allele of the Cdx-2 G > A polymorphism (rs11568820) shows higher transcriptional activity, while the Cdx-2 G allele is associated with decreased VDR functional activity (OchsBalcom et al., 2008).

The A allele in position 1A-1012 (rs4516035) also contributes to different physiological processes and disorders, and may indirectly promote a GATA-3-driven T-cell switch from naive to T-helper 2 cells; this allele may influence susceptibility and metastasis under the influence of transcription factors secreted by different cellular backgrounds (Halsall et al., 2009). SNPs at the -1012 locus may be correlated with height and serum calcium concentration, in contrast with the results of our study. The -1012A VDR promoter increases VDR transcriptional activity and promotes growth and modulated calcium homeostasis independent of calcium/milk intake (Sandoval et al., 2014). Dempfle et al. (2006) reported that SNPs at the -1012 locus are strongly over-transmitted to females, while d'Alesio et al. (2005) linked the effect of the VDR genotype on the height of adolescent girls with an increased level of IGF-1 in haplotypes containing the -1012A VDR promoter.

This study further elucidates the pathogenesis of ISS and predicts therapeutic effects that could facilitate the development of strategies to reduce unguided treatment and patient pain. In the future, children with ISS may be identified for treatment based on genetic analyses. A limitation of this study is its small sample size. However, our study included subjects from different ethnicities, with the genotype composition ratios differing greatly between the Chinese and Korean children with ISS.

In summary, polymorphisms in the VDR promoter polymorphisms (rs11568820, rs4516035) may not be responsible for the pathogenesis of ISS in Chinese children. The A/G genotype has a significantly higher growth velocity compared to the $\mathrm{G} / \mathrm{G}$ genotype, and may serve as a short-term marker of growth potential.

\section{Conflicts of interest}

The authors declare no conflict of interest.

\section{ACKNLOWLEDGMENTS}

This research carried out at Third Affiliated Hospital of Zhengzhou University, and was supported by the Research Fund of Creative Talents in Henan Province Health Engineering.

\section{REFERENCES}

Ambler GR, Fairchild J and Wilkinson DJ (2013). Debate: idiopathic short stature should be treated with growth hormone. J. Paediatr. Child Health 49: 165-169.

Atoum MF and Tchoporyan MN (2014). Association between circulating vitamin D, the Taq1 vitamin D receptor gene polymorphism and colorectal cancer risk among Jordanians. Asian Pac. J. Cancer Prev. 15: 7337-7341. 
Casado-Díaz A, Cuenca-Acevedo R, Navarro-Valverde C, Diaz-Molina C, et al. (2013). Vitamin D status and the Cdx2 polymorphism of the vitamin $\mathrm{D}$ receptor gene are determining factors of bone mineral density in young healthy postmenopausal women. J. Steroid Biochem. Mol. Biol. 136: 187-189.

Choi SK, Park MS, Song JK, Yoon KS, et al. (2013). Association of polymorphisms in the vitamin D receptor promoter with idiopathic short stature. J. Korean Med. Sci. 28: 1329-1333.

d'Alésio A1, Garabédian M, Sabatier JP, Guaydiere-Souquieres G, et al. (2005). Two single-nucleotide polymorphisms in the human vitamin D receptor promoter change protein-DNA complex formation and are associated with height and vitamin D status in adolescent girls. Hum. Mol. Genet. 14: 3539-3548.

Dempfle A, Wudy SA, Saar K, Haagemann S, et al. (2006). Evidence for involvement of the vitamin D receptor gene in idiopathic short stature via a genome-wide linkage study and subsequent association studies. Hum. Mol. Genet. 15: $2772-2783$.

Gao L, Tao Y, Zhang L and Jin Q (2010). Vitamin D receptor genetic polymorphisms and tuberculosis: updated systematic review and meta-analysis. Int. J. Tuberc. Lung Dis. 14: 15-23.

Giordano M, Godi M, Mellone S, Petri A, et al. (2008). A functional common polymorphism in the vitamin D-responsive element of the GH1 promoter contributes to isolated growth hormone deficiency. J. Clin. Endocrinol. Metab. 93: 1005-1012.

Halsall JA, Osborne JE, Epstein MP, Pringle JH, et al. (2009). The unfavorable effect of the A allele of the vitamin D receptor promoter polymorphism A-1012G has different mechanisms related to susceptibility and outcome of malignant melanoma. Dermatoendocrinology 1: 54-57.

Ismail NA, Metwaly NS, El-Moguy FA, Hafez MH, et al. (2011). Growth response of Egyptian children with idiopathic short stature during four years of growth hormone therapy. Indian J. Hum. Genet. 17: 218-225.

Jehan F, Gaucher C, Nguyen TM, Walrant-Debray O, et al. (2008). Vitamin D receptor genotype in hypophosphatemic rickets as a predictor of growth and response to treatment. J. Clin. Endocrinol. Metab. 93: 4672-4682.

Jehan F, Voloc A, Esterle L, Walrant-Debray O, et al. (2010). Growth, calcium status and vitamin D receptor (VDR) promoter genotype in European children with normal or low calcium intake. J. Steroid Biochem. Mol. Biol. 121: $117-120$.

Kaarthikeyan G, Jayakumar ND, Padmalatha O, Varghese S, et al. (2013). Analysis of association of TaqI VDR gene polymorphism with chronic periodontitis in Dravidian ethnicity. Indian J. Hum. Genet. 19: 465-468.

Kalman B and Toldy E (2014). Genomic binding sites and biological effects of the vitamin D: VDR complex in multiple sclerosis. Neuromol. Med. 16: 265-279.

Liao L, Chen X, Wang S, Parlow AF, et al. (2008). Steroid receptor coactivator 3 maintains circulating insulin-like growth factor I (IGF-I) by controlling IGF-binding protein 3 expression. Mol. Cell. Biol. 28: 2460-2469.

Minamitani K, Takahashi Y, Minagawa M, Yasuda T, et al. (1998). Difference in height associated with a translation start site polymorphism in the vitamin D receptor gene. Pediatr. Res. 44: 628-632.

Ochs-Balcom HM, Cicek MS, Thompson CL, Tucker TC, et al. (2008). Association of vitamin D receptor gene variants, adiposity and colon cancer. Carcinogenesis 29: 1788-1793.

Orlow I, Roy P, Reiner AS, Yoo S, et al. (2012). Vitamin D receptor polymorphisms in patients with cutaneous melanoma. Int. J. Cancer 130: 405-418.

Poon AH, Mahboub B and Hamid Q (2013). Vitamin D deficiency and severe asthma. Pharmacol. Ther. 140: 148-155.

Rowland GW, Schwartz GG, John EM and Ingles SA (2012). Calcium intake and prostate cancer among African Americans: effect modification by vitamin D receptor calcium absorption genotype. J. Bone Miner. Res. 27: 187-194.

Sandoval GTV, Jaimes GC, Barrios MC, Cespedes C, et al. (2014). SHOX gene and conserved noncoding element deletions/duplications in Colombian patients with idiopathic short stature. Mol. Genet. Genomic Med. 2: 95-102.

Sotos JF and Tokar NJ (2014). Growth hormone significantly increases the adult height of children with idiopathic short stature: comparison of subgroups and benefits. Int. J. Pediatr. Endocrinol. 2014: 15.

Wit JM, Clayton PE, Rogol AD, Savage MO, et al. (2008). Idiopathic short stature: definition, epidemiology, and diagnostic evaluation. Growth Horm. IGF Res. 18: 89-110. 